\title{
Effects of Filler Size on the Mechanical Properties of Polymer-filled Dental Composites: A Review of Recent Developments
}

\author{
Fathie Kundie, ${ }^{1,3 *}$ Che Husna Azhari, ${ }^{1}$ Andanastuti Muchtar ${ }^{1}$ and Zainal Arifin Ahmad ${ }^{2}$ \\ ${ }^{1}$ Department of Mechanical and Materials Engineering, Faculty of Engineering and Built \\ Environment, Universiti Kebangsaan Malaysia, 43600 UKM Bangi, Selangor, Malaysia \\ ${ }^{2}$ School of Materials and Mineral Resources Engineering, Universiti Sains Malaysia, \\ Engineering Campus, 14300 Nibong Tebal, Pulau Pinang, Malaysia \\ ${ }^{3}$ Department of Dental Technology, College of Medical Technology, \\ P.O. Box 1458, Misurata, Libya
}

*Corresponding author: fathie2@yahoo.com

Published online: 25 April 2018

To cite this article: Kundie, F. et al. (2018). Effects of filler size on the mechanical properties of polymer-filled dental composites: A review of recent developments. J. Phys. Sci., 29(1), 141-165, https://doi.org/10.21315/jps2018.29.1.10

To link to this article: https://doi.org/10.21315/jps2018.29.1.10

\begin{abstract}
Resin composites are widely used in esthetic restorative dentistry. Since their introduction in the mid-1960s, these composites made steady gains in popularity. Their increased use is attributed to their excellent biocompatibility, absence of taste, odour, tissue irritation and toxicity, insolubility in body fluids, easy operation, excellent aesthetic properties, stable colures, optical properties, easy pigmentation, low cost and repairability. The composite resins in current use still suffer from several shortcomings such as poor mechanical properties. In order to improve these properties, microparticles have been used as fillers for a long time. However, the inadequate mechanical properties of resin composites remain problematic. Recently, researchers have utilised nanoparticles as dental composite fillers. This article reviews the relevant literature on the mechanical properties of polymer dental composites filled with micro- and nano-scale particles. The effects of particle size on fracture toughness, flexural strength, and hardness were examined with emphasis on other important factors for improvement. The second section focused on the toughening mechanisms of particulate-polymer composites.
\end{abstract}

Keywords: Polymer dental composites, particle size, nanoparticles, mechanical properties, toughening mechanisms 


\section{INTRODUCTION}

Polymer-based composites have been widely used in dentistry since their introduction in the late 1950s. Recently, nano-composites were introduced as dental polymers. ${ }^{1,2}$ Resin composites are widely used in dentistry as restorative materials, cavity liners, pit and fissure sealants, cores and buildups, inlays, onlays, crowns, veneers, denture teeth, provisional restorations, cements for single or multiple tooth prostheses and orthodontic devices, endodontic sealers, root canal posts, structured scaffolds, and plates and screws. ${ }^{3-5}$ Excellent biocompatibility, superior aesthetic qualities as fillings, moderate cost compared with ceramics, and strong bonding ability to the tooth structure, make resin composite the preferred material in dental restorative applications. ${ }^{1,6,7}$ Most dental composites consist of an organic matrix (polymer phase), inorganic fillers (dispersed phase) and interphase (coupling agent). ${ }^{8}$ Usually, the organic matrix is based on methacrylates, epoxy and polyethylene. ${ }^{9-11}$ The filler is added to enhance polymer properties and usually consists of different compositions, sizes and size distributions of glass or ceramic particles, nanotubes, whiskers, fibres and nanoclusters. ${ }^{12,13}$

The coupling agent such as silane is designed to strongly bond the matrix to the filler, thus improving composite performance. The most commonly used silane in dental restorative composites is 3-methacryloxypropyltrimethoxysilane ( $\gamma$-MPS). Filler content, type, shape, size and morphology are important factors enhancing the desirable mechanical properties of dental composites. ${ }^{14}$ Multiple fillers have been employed in dental composites to improve strength, toughness and durability. However, some problems continue to persist, such as inadequate mechanical properties, water uptake, polymerisation shrinkage, and poor wear resistance of large occlusal restorations during use. ${ }^{1,15,16}$ Dental composites fail because of surface and/or bulk cracks, degradation of the matrix and fillers, water uptake, and insufficient mechanical properties. ${ }^{14}$ The degradation of the bond between the fillers and resin after long-term water absorption is the main reason for the failure of dental composites. ${ }^{17}$

Adding filler nanoparticles to the resin matrix of dental composites improves aesthetic, optical and mechanical properties, such as tensile strength and resistance to fracture, as well as reduces polymerisation shrinkage. ${ }^{18}$ Moreover, nanoparticles enhance wear resistance and gloss retention and also improve the fatigue properties of dental composites. ${ }^{7}$ Reduced interparticle spacing may increase obstacles for dislocation motions and decrease strain localisation. ${ }^{19}$ However, nano-composite properties are significantly affected by various factors, including the degree of conversion of the polymer matrix and interphase, which requires a high level of silanisation because of the high surface area of nanoparticles. ${ }^{19,20}$ This review 
focuses on several mechanical properties of dental composites, namely fracture toughness, flexural strength and hardness. However, the effect of particle/matrix interface adhesion and particle loading on the mechanical properties of polymer dental composites are not covered here. Fracture toughness strongly depends on toughening mechanisms, such as crack deflection, crack pinning, matrix-filler interactions and crack bridging, which increase crack propagation resistance.

Fillers with smaller particle sizes can improve flexural strength because of increased particle surface area, which results in a high surface energy at the fillermatrix interface. Hardness is readily improved by adding either micro- or nanoparticles because rigid inorganic particles generally have considerably higher stiffness than polymer matrices. The novelty of the present paper is that, no review has been done on the effects of different scales of fillers (i.e., nano- and microfillers) on the mechanical properties (fracture toughness, flexural strength and hardness) of polymeric dental composites. It elaborates on the effects of toughening mechanisms in improving the mechanical properties of particulatepolymer composites at these two scales. This review article aims to present the results of recent efforts to improve the mechanical properties of polymer-filled dental composites, compare and discuss in depth the reinforcing effects of nanoand micro-particles, as well as provide some basic understanding of the toughening mechanisms of these composites. To our knowledge, no review papers on these topics have been published yet.

\section{THE EFFECT OF PARTICLE SIZE ON MECHANICAL PROPERTIES}

\subsection{The Effect of Particle Size on Fracture Toughness}

Fracture toughness is a fundamental property of material to predict the strength of material when a crack is present. ${ }^{21}$ It is expressed with the critical stress intensity $K_{\mathrm{IC}}{ }^{22}$ The crack driving force and critical value (fracture toughness) are equated, to obtain the relationship between applied load, crack size and structure geometry which provide the necessary information on structural design. ${ }^{23}$ The units of $K_{\mathrm{IC}}$ are units of stress (force/length $\left.{ }^{2}\right) \times$ units of length $^{1 / 2}$, or force $\times$ length $^{-3 / 2}$ and are often reported as $\mathrm{MNm}^{-3 / 2}$ or $\mathrm{MPa} \mathrm{m}{ }^{1 / 2} .{ }^{24}$ The measurement of this fracture mechanics was applied to a number of problems associated with dental materials. It analysed the behaviour of materials containing cracks or flaws. These flaws and cracks may grow naturally or nucleated after a time in service, and sudden fractures can occur at stresses below the yield stress. Such fractures exist in brittle materials that are unable to plastically deform and redistribute stresses. The fracture mechanics analyses are performed during these types of failures. ${ }^{5}$ In the neat resin, there is 
a high stress concentration in front of the notch. Whereas composites with welldistributed nanoparticle have more uniform stress distribution, thus enhancing the toughness. ${ }^{25}$

Incorporating fillers in the polymer matrix increases fracture toughness, elastic modulus and tensile strength. ${ }^{5,26}$ Particle size has a distinct effect on the mechanical properties of particulate-polymer composites. ${ }^{27,28} \mathrm{Fu}$ et al. reported that particle size significantly affected the fracture toughness of particulate-filled polymer composites. ${ }^{27}$ According to Tanimoto et al., increasing filler particle size increased the fracture toughness of resin-modified glass ionomers. ${ }^{29}$ Ornaghi et al. also found that the fracture toughness of resin composite containing $78 \mathrm{wt} \%$ glass particles with a size of $1.9 \mu \mathrm{m}$ was higher than that of resin composites containing smaller particles; they attributed the increase in fracture toughness to crack deflection. ${ }^{30}$ Asar et al. found that adding $\mathrm{Al}_{2} \mathrm{O}_{3}, \mathrm{TiO}_{2}$ and $\mathrm{ZrO}_{2}$ fillers with average sizes of 12.4, 9.6 and $8.6 \mu \mathrm{m}$, respectively, at different percentages $\left(1 \% \mathrm{TiO}_{2}\right.$ and $1 \% \mathrm{ZrO}_{2}$, $2 \mathrm{wt} \% \mathrm{Al}_{2} \mathrm{O}_{3}, 2 \mathrm{wt} \% \mathrm{TiO}_{2}$ and $2 \mathrm{wt} \% \mathrm{ZrO}_{2}$ ) significantly increased the fracture toughness of poly(methyl methacrylate) (PMMA) denture base composites. ${ }^{31} \mathrm{In}$ the study, the fracture toughness of the test groups was significantly higher than that of control group $(p<0.05)$. The test group containing $2 \mathrm{wt} \% \mathrm{ZrO}_{2}$ had the highest fracture toughness among all groups $(p<0.05)$ and increased fracture toughness by $30 \%$ compared with the control group. ${ }^{31}$

Alhareb et al. reported an improvement in the fracture toughness of PMMA denture base reinforced with nitrile-butadiene rubber (NBR) particles, $\mathrm{Al}_{2} \mathrm{O}_{3}$ and yttria-stabilised zirconia (YSZ) fillers with average particle sizes of $>150,4.4$ and $1.05 \mu \mathrm{m}$, respectively. ${ }^{32}$ In another study, adding up to $50 \mathrm{wt} \%$ glass particles with average sizes of 105-210 $\mu \mathrm{m}$ to acrylic bone cement significantly increased fracture toughness. ${ }^{33}$ Dental composites filled with nanoparticles showed enhanced fracture toughness. ${ }^{34}$ Nanoparticle fillers can be dispersed uniformly in polymer matrix, which increases fracture toughness compared with micro-filled polymer composites..$^{35,36}$ Theoretical results obtained by Chan et al. indicated an increase in fracture toughness of dental composites because of silanisation and nanoparticle loadings.$^{37}$ Ahmed and Ebrahim concluded that adding nano-sized $\mathrm{ZrO}_{2}$ particles significantly increased the fracture toughness of PMMA denture base. ${ }^{38}$ The fracture toughness of PMMA resin for provisional restorations, increased remarkably with addition of $0.25 \mathrm{wt} \%$ of $\mathrm{SiO}_{2}$ nanoparticles with average size of $12 \mathrm{~nm} .{ }^{39}$

Watanabe et al. demonstrated that hybrid and nanoparticle composites had significantly higher fracture toughness compared with micro-filled composites, particularly at high-volume fractions ${ }^{40}$ Hosseinalipour et al. investigated the mechanical properties of bisphenol A-glycidyl methacrylate/triethylene glycol 
dimethacrylate (Bis-GMA/TEGDMA) dental composites reinforced with $\mathrm{SiO}_{2}$ nanoparticles with sizes of $20-50 \mathrm{~nm}$. Their results showed significantly increased mechanical properties compared with a conventional composite control containing $\mathrm{SiO}_{2}$ particles with sizes of 10-40 $\mu \mathrm{m}$. The fracture toughness of GMA/TEGDMA dental composite remarkably increased compared with that of the control when the weight fraction of the filler increased to $40 \mathrm{wt} \%$, indicating the significance of the filler weight fraction in determining the mechanical properties of composites. ${ }^{7}$ However, Elsaka et al. reported that glass ionomer filled with $3 \mathrm{wt} \%$ and $5 \mathrm{wt} \%$ $\mathrm{TiO}_{2}$ nanoparticles with average sizes of $21 \mathrm{~nm}$ had improved fracture toughness compared with the unmodified glass ionomer. ${ }^{41}$ These findings are supported by Protopapa et al., who observed a significant increase in the fracture toughness of PMMA dental composite filled with a low-volume fraction of nanodiamond particles. ${ }^{42}$ Table 1 shows the effects of filler size on the fracture toughness of dental composites.

Table 1: The effect of filler size on fracture toughness of dental composites.

\begin{tabular}{|c|c|c|}
\hline Author (year) & Average particle size & Effect on fracture toughness \\
\hline Alhareb et al. $(2015)^{32}$ & $\begin{array}{l}\operatorname{NBR}(>150 \mu \mathrm{m}) \\
\mathrm{Al}_{2} \mathrm{O}_{3}(4.4 \mu \mathrm{m}) \\
\mathrm{YSZ}(1.05 \mu \mathrm{m})\end{array}$ & Significant increase \\
\hline Asar et al. $(2013)^{31}$ & $\mathrm{ZrO}_{2}(8.6 \mu \mathrm{m})$ & Significant increase \\
\hline Hosseinalipour et al. $(2010)^{7}$ & $\mathrm{SiO}_{2}(20-50 \mathrm{~nm})$ & Significant increase \\
\hline Watanabe et al. $(2008)^{40}$ & $\mathrm{SiO}_{2}(5-20 \mathrm{~nm})$ & Significant increase \\
\hline Ahmed and Ebrahim $(2014)^{38}$ & $\mathrm{ZrO}_{2}(5-15 \mathrm{~nm})$ & Significant increase \\
\hline Protopapa et al. $(2011)^{42}$ & $\begin{array}{l}\text { Diamond }(4-6 \mathrm{~nm}) \text {, } \\
\text { clusters }(20-60 \mathrm{~nm})\end{array}$ & Significant increase \\
\hline Topouzi et al. $(2017)^{39}$ & $\mathrm{SiO}_{2}(12 \mathrm{~nm})$ & Significant increase \\
\hline Ornaghi et al. $(2014)^{30}$ & Glass $(1.9 \mu \mathrm{m})$ & Increase \\
\hline Chan et al. $(2007)^{37}$ & $\mathrm{SiO}_{2}(40-120 \mathrm{~nm})$ & Increase \\
\hline Elsaka et al. $(2011)^{41}$ & $\mathrm{TiO}_{2}(21 \mathrm{~nm})$ & Increase \\
\hline Balos et al. $(2014)^{103}$ & $\mathrm{SiO}_{2}$ agglomerates $(50 \mathrm{~nm})$ & Increase \\
\hline
\end{tabular}

As shown in Table 1, incorporating a low content of large microparticles and a high content of smaller microparticles can increase fracture toughness. In addition, the fracture toughness of nano-composites depends on loading. Composites filled with low concentrations of nanoparticles have high fracture toughness, whereas composites filled with high loadings have low fracture toughness. Filler particles in dental restorative materials substantially enhance fracture toughness by increasing crack propagation resistance via several possible toughening mechanisms, such 
as crack deflection, crack pinning/bowing, matrix-filler interactions and crack bridging. ${ }^{26,43-46}$ Silanisation and nanoparticles improve the fracture toughness of dental polymer nano-composites through a combination of enhanced interface toughness through silanisation, crack deflection and crack bridging. ${ }^{35}$ The fracture toughness of dental composites can be increased by improving the interfacial bond between the nanoparticles and matrix through a larger surface area-to-volume ratio and high particle strength. ${ }^{37} \mathrm{Du}$ et al. illustrated that $\mathrm{Al}_{2} \mathrm{O}_{3}$ nanoparticles $(8 \mathrm{~nm})$ with fixed filler content $(1 \mathrm{wt} \%)$ were well dispersed in polyester resin and promoted crack front trapping that increased fracture toughness. ${ }^{47}$ The increase of volume-specific debonding energy also increases crack resistance with reduced particle size. Particles near the crack plane under high stresses are too small to be debonded from the matrix, indicating the importance of particle size distribution. ${ }^{48}$ To summarise, filler particle size significantly affects the fracture toughness of polymer dental composites. This property of dental composites can be improved by incorporating nanoparticle fillers at low concentrations, in addition to several factors.

\subsection{The Effect of Particle Size on Flexural Strength}

The addition of ceramic fillers to dental composites improves flexural strength. ${ }^{49,50}$ The particle size of fillers significantly affects the mechanical properties of particulate-polymer composites. ${ }^{28,51}$ Incorporating $50 \mathrm{wt} \% \mathrm{Al}_{2} \mathrm{O}_{3}(<10 \mu \mathrm{m})$ in dental composites increased flexural strength by more than $100 \%{ }^{52}$ Tanimoto et al. reported that adding $70 \mathrm{wt} \% \mathrm{SiO}_{2}(3.3 \mu \mathrm{m})$ increased the flexural strength of dental composites, whereas adding larger microparticles reduced flexural strength $(4.3,7.9$ and $15.5 \mu \mathrm{m}){ }^{29}$ Two similar studies also reported that adding HA $(18.1 \mu \mathrm{m})$ to PMMA denture base reduced flexural strength. ${ }^{53,54}$ According to Oral et al., the flexural strength of groups reinforced with large microparticles $(>315 \mu \mathrm{m})$ decreased. ${ }^{55}$ Table 2 shows the effect of microparticles on the flexural strength of dental composites.

Table 2: The effect of microparticles on flexural strength of dental composites.

\begin{tabular}{lll}
\hline \multicolumn{1}{c}{ Author (year) } & \multicolumn{1}{c}{ Average particle size } & Effect on flexural strength \\
\hline Foroutan et al. $(2011)^{52}$ & $\mathrm{Al}_{2} \mathrm{O}_{3}(<10 \mu \mathrm{m})$ & Increase \\
Tanimoto et al. $(2006)^{29}$ & $\mathrm{SiO}_{2}(3.3 \mu \mathrm{m})$ & Increase \\
Lauke $(2008)^{48}$ & $\mathrm{HA}(18.1 \mu \mathrm{m})$ & Decrease \\
Tham et al. $(2010)^{54}$ & $\mathrm{HA}(18.1 \mu \mathrm{m})$ & Decrease \\
Oral et al. $(2014)^{55}$ & $\begin{array}{l}\text { Bioactive glass }(315 \text { to } 1000 \mu \mathrm{m}) \text { and } \\
\text { biostable glass }(915 \text { to } 1000 \mu \mathrm{m})\end{array}$ & Decrease \\
\hline
\end{tabular}


As shown in Table 2, composites reinforced with high-volume fractions of small microparticles have high flexural strength values. The improvement in flexural strength can be attributed to the increased surface area of filler particles because of reduced particle size, which results in high surface energy at the filler-matrix interface. Meanwhile, the reduction in flexural strength can be attributed to the following factors:

1. Increased stress concentration at the interface between the filler and polymer matrix as a result of increased particle size. ${ }^{29}$

2. Poor interfacial interaction between the matrix and filler. Mechanical interlocking is the only bonding mechanism holding the filler in the matrix because of the cooling shrinkage of the matrix. ${ }^{54}$

3. Agglomerations of the filler act as stress concentration points and lead to inefficient stress distribution; therefore, more stress is concentrated on adjacent particles, causing cracks in the material..$^{53,54}$

4. Agglomerations restrict molecular motion in the polymer under load-bearing applications, causing deformation. ${ }^{54}$

5. Presence of particle-matrix interfacial defects. ${ }^{53}$

Dental composites containing nanoparticles have improved mechanical properties, such as flexural strength, compressive strength and wear resistance, compared with traditional micro-composites. ${ }^{56,57}$ According to Foroutan et al., dental nanocomposites reinforced with three loadings $(10,20$ and $30 \mathrm{wt} \%)$ of $\mathrm{Al}_{2} \mathrm{O}_{3}(25-40$ $\mathrm{nm}$ ) had significantly increased flexural strength. ${ }^{52}$ Two similar studies evaluated the effects of adding $\mathrm{TiO}_{2}$ nanoparticles $(<20 \mathrm{~nm}$ and $21 \mathrm{~nm})$ to dental composites at different low loadings ( $<20 \mathrm{~nm}: 0.5$ and $1 \mathrm{wt} \% ; 21 \mathrm{~nm}: 3,5$ and $7 \mathrm{wt} \%) .{ }^{41,58}$ Lower filler contents significantly increased flexural strength. Moreover, Hosseinalipour et al. investigated the mechanical properties of Bis-GMA/TEGDMA dental composite reinforced with several loadings $(20,30,40$ and $50 \mathrm{wt} \%)$ of $\mathrm{SiO}_{2}$ nanoparticles $(20-50 \mathrm{~nm})$. They found a significant increase in flexural strength at a loading of $40 \mathrm{wt} \%{ }^{7}$ Similarly, Barghamadi et al. incorporated $\mathrm{SiO}_{2}$ nanoparticles into Bis-GMA/TEGDMA. The first composite consisted of filler $(12 \mathrm{~nm})$ with loadings of 15, 20, 25 and $30 \mathrm{wt} \%$, whereas the second consisted of filler (40 nm) with loadings of $25,35,45,50$ and $53 \mathrm{wt} \%$. Flexural strength increased at a volume fraction up to $25 \%$ and $45 \%$ for the first and second composite, respectively. ${ }^{59}$

Many researchers had attempted to enhance the mechanical properties of PMMA denture base. A recent study by Ahmed and Ebrahim evaluated the flexural strength of PMMA denture base reinforced with different low concentrations 
$(1.5,3,5$ and $7 \mathrm{wt} \%)$ of $\mathrm{ZrO}_{2}$ nanoparticles $(2-15 \mathrm{~nm})$. Their results revealed that flexural strength significantly increased at a filler percentage of $7 \mathrm{wt} \%{ }^{38} \mathrm{In}$ another recent study, researchers used filler mixtures of $\mathrm{HA} / \mathrm{Al}_{2} \mathrm{O}_{3}(30 / 80 \mathrm{~nm})$. The mixture consisted of $\mathrm{HA}(5 \mathrm{wt} \%$ and $10 \mathrm{wt} \%)$ and each percentage was added to $1 \%$ of $\mathrm{Al}_{2} \mathrm{O}_{3}$ (i.e., $0,3,6$ and $8 \mathrm{wt} \%$ ). The hybrid nano-composites with $5 \mathrm{wt} \%$ and $10 \mathrm{wt} \%$ of $\mathrm{HA}$ and $6 \mathrm{wt} \%$ of $\mathrm{Al}_{2} \mathrm{O}_{3}$ had the maximum flexural strength. ${ }^{60}$ Two similar studies evaluated the effects of incorporating silver (Ag) particles $\left(38 \mathrm{~nm}\right.$ ) into PMMA denture base. ${ }^{61,62} \mathrm{Ag}$ filler was incorporated at very low loadings $(0.5 \mathrm{wt} \%)$ and $(0.05 \mathrm{wt} \%$ and $0.2 \mathrm{wt} \%)$. The results showed an insignificant increase in flexural strength. Table 3 shows the positive effects of nanoparticles on the flexural strength of dental composites.

Table 3: The positive effect of nanoparticles on flexural strength of dental composites.

\begin{tabular}{lll}
\hline \multicolumn{1}{c}{ Authors (year) } & Average particle size & Effect on flexural strength \\
\hline Foroutan et al. $(2011)^{52}$ & $\mathrm{Al}_{2} \mathrm{O}_{3}(25-40 \mathrm{~nm})$ & Significant increase \\
Elsaka et al. $(2011)^{41}$ & $\mathrm{TiO}_{2}(21 \mathrm{~nm})$ & Significant increase \\
Xia et al. $(2008)^{58}$ & $\mathrm{TiO}_{2}(<20 \mathrm{~nm})$ & Significant increase \\
Hosseinalipour et al. $(2010)^{7}$ & $\mathrm{SiO}_{2}(20-50 \mathrm{~nm})$ & Significant increase \\
Ahmed \& Ebrahim $(2014)^{38}$ & $\mathrm{ZrO}_{2}(2-15 \mathrm{~nm})$ & Significant increase \\
Safarabadi et al. $(2014)^{60}$ & $\mathrm{HA} / \mathrm{Al}_{2} \mathrm{O}_{3}(30 / 80 \mathrm{~nm})$ & Increase \\
Barghamadi et al. $(2015)^{59}$ & $\mathrm{SiO}_{2}(12 \& 40 \mathrm{~nm})$ & Increase \\
Sodagar et al. $(2012)^{62}$ & $\mathrm{Ag}(38 \mathrm{~nm})$ & Insignificant increase \\
Kassaee et al. $(2008)^{61}$ & $\mathrm{Ag}(38 \mathrm{~nm})$ & Insignificant increase \\
\hline
\end{tabular}

However, a few studies had reported a decrease in flexural strength. Sodagar et al. added $\mathrm{TiO}_{2}(21 \mathrm{~nm}), \mathrm{SiO}_{2}(20 \mathrm{~nm})$ and $\mathrm{TiO}_{2}$ with $\mathrm{SiO}_{2}$ at two concentrations ( $1 \mathrm{wt} \%$ and $0.5 \mathrm{wt} \%$ ) to PMMA. ${ }^{63}$ Hamouda and Beyari also incorporated $\mathrm{TiO}_{2}$ $\left(21 \mathrm{~nm}\right.$ ) into PMMA denture base with a loading of $5 \mathrm{wt} \%{ }^{64}$ Similarly, Shibata et al. added apatite-coated titanium dioxide $\left(\mathrm{Ap}-\mathrm{TiO}_{2}\right)$ to $\mathrm{PMMA}$ denture base at volume fractions of 1,5 and $10 \mathrm{wt} \%{ }^{65}$ Moreover, Garoushi et al. incorporated $\mathrm{SiO}_{2}(20 \mathrm{~nm})$ into micro-filled composite resin with loadings of 10, 15, 20 and $30 \mathrm{wt} \% .{ }^{66}$ The results of these four studies showed that neat resins have higher flexural strength than nano-composites. Table 4 shows the negative effects of nanoparticles on the flexural strength of dental composites. 
Table 4: The negative effect of nanoparticles on flexural strength of dental composites.

\begin{tabular}{|c|c|c|}
\hline Authors (year) & Average particle size & Effect on flexural strength \\
\hline Sodagar et al. $(2012)^{62}$ & $\mathrm{TiO}_{2} / \mathrm{SiO}_{2}(21 / 20 \mathrm{~nm})$ & Decrease \\
\hline Hamouda \& Beyari (2014) & $\mathrm{TiO}_{2}(21 \mathrm{~nm})$ & Decrease \\
\hline Shibata et al. $(2007)^{65}$ & $\mathrm{Ap}-\mathrm{TiO}_{2} / \mathrm{TiO}_{2}(400 \mathrm{~nm})$ & Decrease \\
\hline Garoushi et al. $(2011)^{66}$ & $\mathrm{SiO}_{2}(20 \mathrm{~nm})$ & Decrease \\
\hline
\end{tabular}

As shown in Tables 3 and 4, composites filled with nanoparticles at low/high loadings exhibit high flexural strength, whereas some composites at low loadings have decreased flexural strength. The increased flexural strength of dental composites reinforced with nano-sized fillers can be attributed to five reasons:

1. Nanoparticle have high-specific surface area and high surface energy that help to grab reactive monomer or polymer segment on their surfaces. ${ }^{67-72}$

2. Formation of a strong bond between inorganic fillers and organic matrix. ${ }^{27,35,72}$ This bond is formed by covering the fillers with a functional silane coupling agent, such as MPS, to chemically link fillers with the matrix. ${ }^{35,73,74}$ The chemical linkage contains a siloxane bond between the filler and silane, as well as a covalent bond between the reactive groups of the matrix and organofunctional group of silane. ${ }^{75}$

3. Decreased particle size at the same volume fraction results in covalent linkage, strong physical interaction, and increased contact area, which enhance the interfacial adhesion between matrix and nanofiller. ${ }^{52,72,76,77}$ Furthermore, smaller sizes cause more particles to share the applied stress in a specific region. ${ }^{77}$ These factors result in effective stress transfer from the soft resin to the hard nanofiller. ${ }^{52,72,76,77}$

4. Increased rigidity and decreased ductility of nano-composites result from the addition of highly rigid nanoparticles, such as nano- $\mathrm{Al}_{2} \mathrm{O}_{3}$ and nano- $\mathrm{TiO}_{2}$, as well as the capability of these nanoparticles to withstand higher stresses. ${ }^{72,78,79}$

5. Uniformly dispersed nanoparticles prevent crack propagation and significantly improve flexural strength. ${ }^{27,58,72,80}$

Flexural strength may decrease because of the following reasons:

1. Nano-sized oxides affect the internal structure of polymerised by acting as impurities. ${ }^{60,62,63}$ 
2. Dispersed nanoparticles within the acrylic resin decrease the degree of conversion and increase the amount of residual unreacted monomer that acts as plasticiser. ${ }^{63,65}$

3. Agglomerated nanofillers in the matrix may enhance crack propagation. Under applied load, slippage may exist within the agglomerate. ${ }^{81,82}$ The surface area for the interaction between nanofillers and matrix decreases and fractures in the agglomerate sites are initiated. ${ }^{66,83}$

4. Decreased cross-section of the load-bearing matrix..$^{60,61,84,85}$

5. Changes in the modulus of elasticity of the matrix and crack propagation mode of the sample because of increased filler content. ${ }^{60,61,85}$

6. Void formation from entrapped air and moisture and from increased filler loading. ${ }^{60,61,84-86}$

7. Incomplete wetting of the filler by the matrix..$^{60,61,84,85}$

8. Stress concentration because of higher filler levels. ${ }^{60,61,85}$ However, polymer composition (chemical formulation) also significantly affects flexural strength. ${ }^{62}$ Dental composites showed increased flexural strength when BisGMA or TEGDMA was replaced with urethane dimethacrylate (UDMA) and decreased flexural strength when Bis-GMA was replaced with TEGDMA. ${ }^{87}$

To summarise, low contents of nanoparticles and high contents of small microparticle fillers can increase the flexural strength of dental composites. Particle size should be selected based on the properties affected by the filler volume fraction, such as required viscosity and curing shrinkage. Polymer composition is another factor with a marked effect on flexural strength.

\subsection{The Effect of Particle Size on Hardness}

The presence of filler particles in the resin matrix enhances mechanical properties, such as hardness. ${ }^{88-93}$ The addition of 38.16 micro-sized $\mathrm{Nb}_{2} \mathrm{O}_{5}$ particles to dental adhesive resin with loadings of 5, 10 and $20 \mathrm{wt} \%$ significantly increased hardness at $20 \mathrm{wt} \%$, followed by $10 \mathrm{wt} \%{ }^{94}$ Vojdani et al. incorporated $\mathrm{Al}_{2} \mathrm{O}_{3}$ with an average particle size of $3 \mu \mathrm{m}$ into PMMA denture base; they noted that hardness significantly increased at $2.5 \mathrm{wt} \%$ and $5 \mathrm{wt} \%$, followed by 0.5 $\mathrm{wt} \%$ and $1 \mathrm{wt} \%{ }^{85}$ Variance results showed a decrease in the surface hardness of PMMA denture base reinforced with $10 \mathrm{wt} \%$ and $20 \mathrm{wt} \% \mathrm{ZrO}_{2}$ with particle sizes of 5-10 $\mu \mathrm{m} .{ }^{95}$ Moreover, filler size affects the hardness of composites. ${ }^{96}$ Dental composites reinforced with nanoparticles displayed high hardness values. ${ }^{97-99} \mathrm{Liu}$ 
et al. reported a significant increase in the hardness of dental composite reinforced with $\mathrm{SiO}_{2}$ with a mean size of $30 \mathrm{~nm}$ and filler volume fraction of $1.5 \mathrm{wt} \%{ }^{1}$ In another study, researchers added modified and unmodified $\mathrm{TiO}_{2}$ nanoparticles $(<20 \mathrm{~nm})$ to dental composite at a filler volume fraction of $0.5 \%$ and $1 \%$. Both groups showed increased hardness values. ${ }^{58}$ Moreover, Prentice et al. incorporated $\mathrm{YbF}_{3}$ and $\mathrm{BaSO}_{4}(25 \mathrm{~nm}$ and $<10 \mathrm{~nm})$ in glass ionomer cement at loadings of $1 \mathrm{wt} \%$ and $2 \mathrm{wt} \%$. Both groups reported insignificant increases in hardness values. ${ }^{100}$ Many efforts have been made to improve the mechanical properties of PMMA denture base. ${ }^{101,102}$ Safarabadia et al. evaluated the hardness of PMMA denture base reinforced with hybrid nanofillers consisting of $\mathrm{HA}$ and $\mathrm{Al}_{2} \mathrm{O}_{3}$ $(30 / 80 \mathrm{~nm})$. Their results revealed that $\mathrm{HA} / \mathrm{Al}_{2} \mathrm{O}_{3}(10 / 8 \mathrm{wt} \%)$ significantly increased hardness. ${ }^{60}$ Balos et al. found that using $\mathrm{SiO}_{2}$ with agglomerate size of $50 \mathrm{~nm}$ at very low loading $(0.023 \mathrm{wt} \%)$ increased the hardness of PMMA denture base composites. ${ }^{103}$ Incorporating $\mathrm{ZrO}_{2}$ particles with average sizes of $5-15 \mathrm{~nm}$ in PMMA denture base at different loadings $(1.5,3,5$ and $7 \mathrm{wt} \%)$ significantly increased hardness at $7 \mathrm{wt} \%{ }^{38}$ Table 5 shows the effects of filler size on the hardness of dental composites.

Table 5: The effect of filler size on hardness of dental composites.

\begin{tabular}{lll}
\hline \multicolumn{1}{c}{ Author (year) } & \multicolumn{1}{c}{ Average particle size } & Effect on hardness \\
\hline Leitune et al. $(2013)^{94}$ & $\mathrm{Nb}_{2} \mathrm{O}_{5}(38.16 \mu \mathrm{m})$ & Increase \\
Vojdani et al. $(2012)^{85}$ & $\mathrm{Al}_{2} \mathrm{O}_{3}(3 \mu \mathrm{m})$ & Significant increase \\
Ahmed \& Ebrahim $(2014)^{38}$ & $\mathrm{ZrO}_{2}(5-15 \mathrm{~nm})$ & Significant increase \\
Liu et al. $(2014)^{1}$ & $\mathrm{SiO}_{2}(30 \mathrm{~nm})$ & Significant increase \\
Balos et al. $(2014)^{103}$ & $\mathrm{SiO}_{2}$ agglomerates $(50 \mathrm{~nm})$ & Increase \\
Safarabadia et al. $(2014)^{60}$ & $\mathrm{HA}^{6} \mathrm{Al}_{2} \mathrm{O}_{3}(30 / 80 \mathrm{~nm})$ & Increase \\
Xia et al. $(2008)^{58}$ & $\mathrm{TiO}_{2}(<20 \mathrm{~nm})$ & Increase \\
Prentice et al. $(2006)^{100}$ & $\mathrm{YbF}_{3}(25 \mathrm{~nm}) \& \mathrm{BaSO}_{4}(<10 \mathrm{~nm})$ & Insignificant increase \\
Asopa et al. $(2015)^{95}$ & $\mathrm{ZrO}_{2}(5-10 \mu \mathrm{m})$ & Decrease \\
\hline
\end{tabular}

As shown in Table 5, hardness increased as the filler volume fraction increased. Microparticles improved hardness at relatively higher concentrations than nanoparticles. In addition to particle size, several factors significantly enhance the hardness of dental composites, such as:

1. Inherent properties of some filler particles, such as $\mathrm{Al}_{2} \mathrm{O}_{3}$ and $\mathrm{ZrO}_{2}$. These particles exhibit strong ionic interatomic bonding to confer favourable properties, such as high hardness. ${ }^{1,38,60,85}$ Moreover, $\mathrm{SiO}_{2}, \mathrm{Al}_{2} \mathrm{O}_{3}$ and $\mathrm{TiO}_{2}$ nanoparticles show elastic, rather than plastic, deformation under indentation load. ${ }^{104}$ 
2. Increased filler loading increases hardness values. ${ }^{38,44,105-109}$

3. Strong interfacial interactions between the modified nanoparticles and polymer. ${ }^{45,100,110}$

4. Uniform dispersion of nanoparticles provides enough distances between the particles, increasing composite reinforcement and hardness. ${ }^{45,96}$

5. Harder filler particles exhibit higher surface hardness in the composite. ${ }^{11,112}$ Therefore, filler particle size and filler content, in addition to various factors, can affect the hardness of dental composites.

\section{TOUGHENING MECHANISMS}

\subsection{Crack Deflection}

Crack deflection occurs because of the predominant interparticle/intercluster crack growth in the matrix when the crack is forced to move out of its original plane by tilting or twisting. ${ }^{113-116}$ This leads to increased fracture toughness because of nonplanar cracks. ${ }^{117}$ Crack deflection is a shielding mechanism that increases fracture resistance by reducing the stress intensity factor at the crack tip. ${ }^{113}$ Schematic drawing of crack deflection is shown in Figure 1.

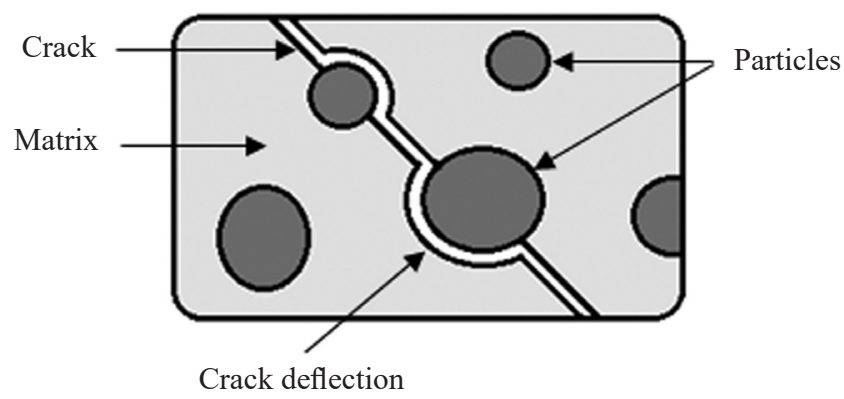

Figure 1: Schematic drawing of crack deflection.

\subsection{Crack Pinning}

This mechanism suggests that when crack propagation meets inorganic particles, crack propagation becomes pinned and bows out between the filler particles by generating secondary cracks. Crack pinning is a significant toughening mechanism, particularly in rigid particulate-reinforced brittle composites. ${ }^{15,117-119}$ This mechanism has been detected in micro- and nano-composites. ${ }^{120,121}$ It occurs easily 
at a nanoscale level, particularly with more reduced interparticle distance resulting from relatively high nanofiller content. ${ }^{119}$ Medina et al. performed fractography on a nano-composite to illustrate that adding nanoparticles induced crack pinning. ${ }^{115}$ Moreover, the river-like lines in the nano-composites possibly resulted from crack pinning and the blocking effects of nanoparticles. ${ }^{119}$ Figure 2 shows a schematic drawing of crack pinning.

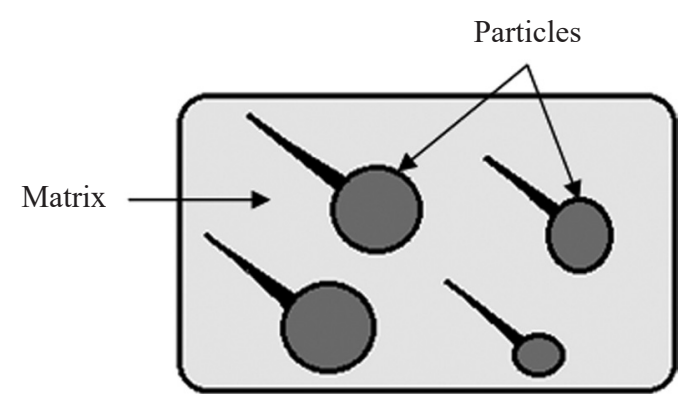

Figure 2: Schematic drawing of crack pinning.

\subsection{Matrix-filler Interactions}

The strength and toughness of the particulate-filled, polymer micro- and nanocomposites are strongly affected by bonding integrity at the filer/matrix interface and thus the stress transfer between the fillers and the matrix. ${ }^{51,122,123}$ Under perfect bonding conditions, a large quantity of energy is consumed at the filler-matrix interface. ${ }^{123,124}$ The existence of a thin and high-strength interphase layer results in effective stress transfer and causes crack deflection and propagation in the matrix. However, a thick and low-strength interphase layer causes crack propagation and crack blunting in the interphase material. ${ }^{125}$ Figure 3 shows a schematic drawing of filler-matrix interphase.

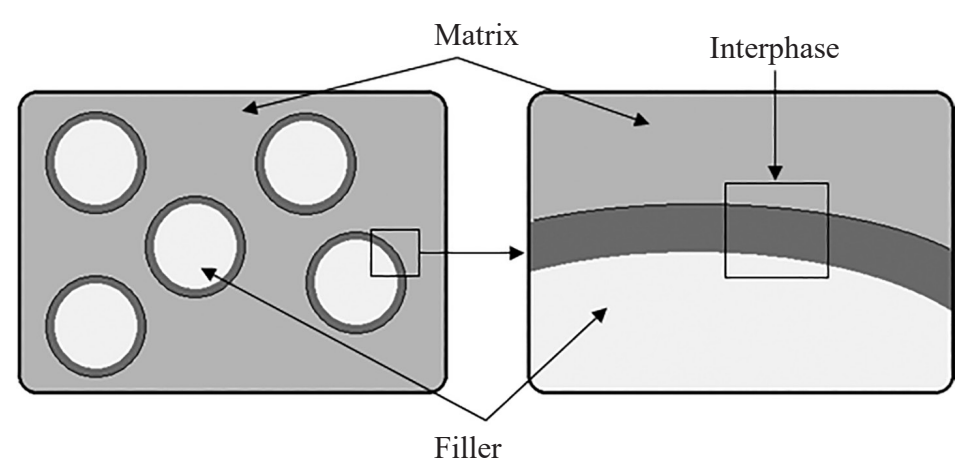

Figure 3: Schematic drawing of filler-matrix interphase. 


\subsection{Crack Bridging}

Crack bridging occurs because of the interparticle/intercluster crack growth when particles connect the crack faces at the crack wake. ${ }^{43,113,116}$ These uncracked bridges sustain part of the load, increasing fracture resistance. ${ }^{114,126}$ Essentially, the crack bridging mechanism minimises the stress concentration at the crack tip and therefore works as an extrinsic toughening source. ${ }^{114}$ Furthermore, when load is increased, a microcrack is created at some distance from the main crack, and an uncracked bridge exists between the microcrack and the main crack. The microcrack occurs very near to the tip of the main crack and grows in both directions, whereas the main crack stops propagating. Finally, both cracks will meet each other because of the extension of the microcrack. Toughening ceases at this point. However, for small particle-filled composites, crack bridging is not an expected powerful factor enhancing toughness. ${ }^{43}$ Crack deflection and bridging often work in harmony, given that crack deflection usually leads to crack bridging. ${ }^{113,114}$ Schematic drawing of crack bridging is shown in Figure 4.

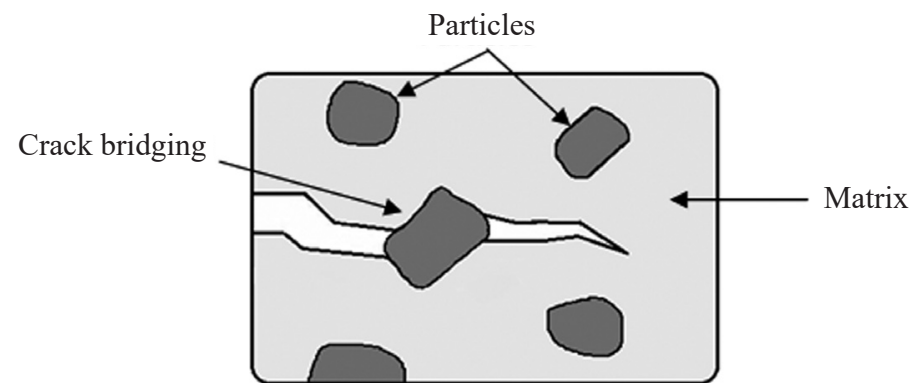

Figure 4: Schematic drawing of crack bridging.

\section{CONCLUSION}

This review article compares and highlights the effects of micro- and nano-scale particles on the mechanical properties, including fracture toughness, flexural strength and hardness, of particulate dental resin composites. Many types of nanofillers, such as $\mathrm{SiO}_{2}, \mathrm{ZrO}_{2}, \mathrm{TiO}_{2}, \mathrm{Al}_{2} \mathrm{O}_{3}, \mathrm{BaSO}_{4} \mathrm{HA}, \mathrm{Ag}, \mathrm{YbF}_{3}$ and nanodiamond, have been used in dental composites. The results of the conducted review showed that the mechanical properties of dental nano-composites with lower filler loadings are superior to microfilled dental composites. The effects of nanoparticles strongly depend on many factors, such as the type and mechanical properties of inorganic nanofillers, uniform dispersal of nanofillers within the polymer matrix, volume fraction of the filler particles, and type of silane used. The key control parameters to enhance fracture toughness are toughening mechanisms (i.e., crack 
deflection, crack pinning/bowing, matrix-filler interactions and crack bridging). Good flexural strength requires effective stress transfer from resin to nanofiller, whereas increased filler volume fraction is needed for adequate hardness.

Therefore, future works on this subject demand a proper and systematic investigation on the effects of particle loading, morphology (shape) and particle/matrix interface adhesion that directly contributed to the enhancement of mechanical properties especially fracture toughness and hardness. The reason is obvious since composite strength depends on the load transfer between filler and matrix, and stiffness depends highly on particle loading. However, specific attention should be made on the particle shape of fillers since it has a remarkable effect on some mechanical properties of the dental composites.

\section{ACKNOWLEDGEMENTS}

The Ministry of Higher Education and Scientific Research, Libya is acknowledged for financially supporting the first author in the form of $\mathrm{PhD}$ scholarship.

\section{REFERENCES}

1. Liu, Y. et al. (2014). Effect of nano $\mathrm{SiO}_{2}$ particles on the morphology and mechanical properties of POSS nanocomposite dental resins. J. Nanopart. Res., 16, 2736, https://doi.org/10.1007/s11051-014-2736-0.

2. Kumari, C., Bansal, R. \& Bhat, K. (2016). Evaluation of surface roughness of different restorative composites after polishing using atomic force microscopy. J. Conserv. Dent., 19(1), 56-62, https://doi.org/10.4103/09720707.173200.

3. Ferracane, J. L. (2011). Resin composite: State of the art. Dent. Mater., 27(1), 29-38, https://doi.org/10.1016/j.dental.2010.10.020.

4. Muddugangadhar, B. et al. (2011). Biomaterials for dental implants: An overview. Int. J. Oral Implant., 2(1), 13, https://doi.org/10.5005/jpjournals-10012-1030.

5. Sakaguchi, R. L. \& Powers, J. M. (2012). Craig's restorative dental materials. St. Louis: Elsevier/Mosby.

6. Aydin Sevinç, B. \& Hanley, L. (2010). Antibacterial activity of dental composites containing zinc oxide nanoparticles. J. Biomed. Mater. Res. B Appl. Biomater., 94B(1), 22, https://doi.org/10.1002/jbm.b.31620. 
7. Hosseinalipour, M. et al. (2010). Investigation of mechanical properties of experimental bis-GMA/TEGDMA dental composite resins containing various mass fractions of silica nanoparticles. J. Prosthod., 19(2), 112-117, https://doi.org/10.1111/j.1532-849X.2009.00530.x.

8. Rodriguez-Quiros, H. A. \& Casanova-Yepes, H. F. (2015). Effect of the functionalization of silica nanoparticles as a reinforcing agent on dental composite materials. Rev. Fac. Ing. Rev. Fac. Ingen., 75, 36.

9. Munhoz, T. et al. (2017). Effect of nanoclay addition on physical, chemical, optical and biological properties of experimental dental resin composites. Dent. Mater., 33(3), 271-279, https://doi.org/10.1016/j.dental.2016.11.016.

10. Lamichhane, A., Xu, C. \& Zhang, F.-Q. (2014). Dental fiber-post resin base material: A review. J. Adv. Prosthod., 6(1), 60-65, https://doi.org/10.4047/ jap.2014.6.1.60.

11. Ramakrishna, S. et al. (2001). Biomedical applications of polymer-composite materials: A review. Compos. Sci. Technol., 61(9), 1189-1224, https://doi. org/10.1016/S0266-3538(00)00241-4.

12. Graciano, F. M. O. et al. (2012). Evaluation of translucency of a nanofilled and a microhybrid resin composites. Braz. Dent. Sci., 15(3), 38-42.

13. Habib, E. et al. (2015). Inorganic fillers for dental resin composites: Present and future. ACS Biomater. Sci. Eng., 2(1), 1, https://doi.org/10.1021/ acsbiomaterials.5b00401.

14. Mohseni, M. et al. (2016). Effect of plate-like glass fillers on the mechanical properties of dental nanocomposites. Iran Polym. J., 25(2), 129-134, https://doi.org/10.1007/s13726-015-0407-3.

15. Kim, J. et al. (2006). Characteristics of novel dental composites containing 2, 2-bis [4-(2-methoxy-3-methacryloyloxy propoxy) phenyl] propane as a base resin. Biomacromol., 7(1), 154, https://doi.org/10.1021/bm0504911.

16. Leprince, J. et al. (2010). Investigating filler morphology and mechanical properties of new low-shrinkage resin composite types. J. Oral Rehab., 37(5), 364-376, https://doi.org/10.1111/j.1365-2842.2010.02066.x.

17. Wang, W. et al. (2014). Structure-property relationships in hybrid dental nanocomposite resins containing monofunctional and multifunctional polyhedral oligomeric silsesquioxanes. Int. J. Nanomed., 9(1), 841-852, https://doi.org/10.2147/IJN.S56062.

18. Sachdeva, S. et al. (2014). Nano-composite dental resins: An overview. Ann. Dent. Special., 3(2), 52.

19. Kim, J., Kim, L. \& Kim, C. (2007). Size control of silica nanoparticles and their surface treatment for fabrication of dental nanocomposites. Biomacromol., 8(1), 215, https://doi.org/10.1021/bm060560b. 
20. Sideridou, I. D. \& Karabela, M. M. (2009). Effect of the amount of 3-methacyloxypropyltrimethoxysilane coupling agent on physical properties of dental resin nanocomposites. Dent. Mater., 25(11), 1315-1324, https://doi.org/10.1016/j.dental.2009.03.016.

21. Petterson, R. W. \& Bodig, J. (2007). Prediction of fracture toughness of conifers. Wood Fib. Sci., 15(4), 302

22. Pippan, R. \& Hohenwarter, A. (2016). The importance of fracture toughness in ultrafine and nanocrystalline bulk materials. Mater. Res. Lett., 4(3), 127136, https://doi.org/10.1080/21663831.2016.1166403.

23. Gdoutos, E. E. (2012). Fracture mechanics criteria and applications. New York: Springer.

24. Craig, R. G. (2002). Restorative dental materials. St. Louis: Mosby.

25. Friedrich, K., Fakirov, S. \& Zhang, Z., (2005) Polymer composites: From nano- to macro-scale. London: Springer Science and Business Media, https://doi.org/10.1007/b137162.

26. Belli, R. et al. (2014). Strengthening of dental adhesives via particle reinforcement. J. Mech. Behav. Biomed. Mater, 37, 100-108, https://doi. org/10.1016/j.jmbbm.2014.05.007.

27. Ellakwa, A. E., Morsy, M. A. \& El-Sheikh, A. M. (2008). Effect of aluminum oxide addition on the flexural strength and thermal diffusivity of heat-polymerized acrylic resin. J. Prosthodont., 17(6), 439-444, https://doi. org/10.1111/j.1532-849X.2008.00318.x.

28. Omar, M. F., Akil, H. M. \& Ahmad, Z. A. (2012). Particle size: Dependent on the static and dynamic compression properties of polypropylene/ silica composites. Mater. Des., 45, 539-547, https://doi.org/10.1016/j. matdes.2012.09.026.

29. Tanimoto, Y. et al. (2006). Experimental and computational approach for evaluating the mechanical characteristics of dental composite resins with various filler sizes. Acta Biomater., 2(6), 633-639, https://doi.org/10.1016/j. actbio.2006.06.006.

30. Ornaghi, B. P. et al. (2014). Fracture toughness and cyclic fatigue resistance of resin composites with different filler size distributions. Dent. Mater, 30(7), 742-751, https://doi.org/10.1016/j.dental.2014.04.004.

31. Asar, N. V. et al. (2013). Influence of various metal oxides on mechanical and physical properties of heat-cured polymethyl methacrylate denture base resins. J. Adv. Prosthod., 5(3), 241-247, https://doi.org/10.4047/ jap.2013.5.3.241.

32. Alhareb, A. O., Akil, H. M. \& Ahmad, Z. A. (2015). Mechanical properties of PMMA denture base reinforced by nitrile rubber particles with $\mathrm{Al}_{2} \mathrm{O}_{3} /$ YSZ fillers. Proced. Manuf., 2, 301-306, https://doi.org/10.1016/j. promfg.2015.07.053 
33. Sajjadi, S. A. (2015). A study on the effect of nano alumina particles on fracture behavior of PMMA. Technol., 3(2), 94-102.

34. Yeli, M. et al. (2010). Recent advances in composite resins: A review. J. Oral Res. Rev., 2(1), 134-136.

35. Chen, M.-H. (2010). Update on dental nanocomposites. J. Dent. Res., 89(6), 549-560, https://doi.org/10.1177/0022034510363765.

36. Devaprakasam, D. et al. (2008). Effect of microstructure of nano- and microparticle filled polymer composites on their tribo-mechanical performance. J. Phys. Conf. Ser., 126(1), https://doi.org/10.1088/1742-6596/126/1/012057.

37. Chan, K. S. et al. (2007). Improving fracture toughness of dental nanocomposites by interface engineering and micromechanics. Eng. Fract. Mech., 74(12), 1857-1871, https://doi.org/10.1016/j.engfracmech.2006. 07.013 .

38. Ahmed, M. A. \& Ebrahim, M. I. (2014). Effect of zirconium oxide nanofillers addition on the flexural strength, fracture toughness, and hardness of heat-polymerized acrylic resin.WJNSE, 4(2), article ID 46234, https://doi. org/10.4236/wjnse.2014.42008.

39. Topouzi, M. et al. (2017). Reinforcement of a PMMA resin for interim fixed prostheses with silica nanoparticles. J. Mech. Behav. Biomed. Mater., 69, 213-222, https://doi.org/10.1016/j.jmbbm.2017.01.013.

40. Watanabe, H. (2005). Fracture toughness comparison of six resin composites. Dent. Mater., 24(3), 418-425, https://doi.org/10.1016/j.dental.2007.06.018.

41. Elsaka, S. E., Hamouda, I. M. \& Swain, M. V. (2011). Titanium dioxide nanoparticles addition to a conventional glass-ionomer restorative: Influence on physical and antibacterial properties. J. Dent., 39(9), 589-598, https://doi.org/10.1016/j.jdent.2011.05.006.

42. Protopapa, P. et al. (2011). Reinforcement of a PMMA resin for fixed interim prostheses with nanodiamonds. Dent. Mater. J., 30(2), 222-231, https://doi. org/10.4012/dmj.2010-135.

43. De Souza, J. A. et al. (2011). Fracture resistance curves and toughening mechanisms in polymer based dental composites. J. Mech. Behav. Biomed. Mater., 4(4), 558-571, https://doi.org/10.1016/j.jmbbm.2011.01.003.

44. Manhart, J. et al. (2000). Mechanical properties of new composite restorative materials. J. Biomed. Mater. Res., 53(4), 353-361, https://doi. org/10.1002/1097-4636(2000)53:4\%3C353::AID-JBM9\%3E3.0.CO;2-B.

45. Karthick, R., Sirisha, P. \& Sankar, M. R. (2014). Mechanical and tribological properties of PMMA-sea shell based biocomposite for dental application. Proced. Mater. Sci., 6, 1989-2000, https://doi.org/10.1016/j. mspro.2014.07.234. 
46. Shah, M. B., Ferracane, J. L. \& Kruzic, J. J. (2009). R-curve behavior and toughening mechanisms of resin-based dental composites: Effects of hydration and post-cure heat treatment. Dent. Mater, 25(6), 760-770, https://doi.org/10.1016/j.dental.2008.12.004.

47. Du, Y., Jain, N. \& Shukla, A. (2006). Effect of particle size on fracture behavior of polyester/ $\mathrm{Al}_{2} \mathrm{O}_{3}$ composites. Paper presented at the $2006 \mathrm{SEM}$ Annual Conference \& Exposition on Experimental and Applied Mechanics, 4-7 June, St. Louis.

48. Lauke, B. (2008). On the effect of particle size on fracture toughness of polymer composites. Compos. Sci. Technol., 68(15-16), 3365-3372, https://doi.org/10.1016/j.compscitech.2008.09.011.

49. Le Roux, A. R. (2008). Design and evaluation of alumina/feldspar resin infiltrated dental composite materials. PhD diss., Durban University of Technology, South Africa.

50. Zandinejad, A. A., Atai, M. \& Pahlevan, A. (2006). The effect of ceramic and porous fillers on the mechanical properties of experimental dental composites. Dent. Mater., 22(4), 382-387, https://doi.org/10.1016/j.dental.2005.04.027.

51. Fu, S.-Y. et al. (2008). Effects of particle size, particle/matrix interface adhesion and particle loading on mechanical properties of particulate polymer composites. Compos. B Eng., 39(6), 933-961, https://doi.org/ 10.1016/j.compositesb.2008.01.002.

52. Foroutan, F. et al. (2011). Mechanical properties of dental composite materials reinforced with micro and nano-size $\mathrm{Al}_{2} \mathrm{O}_{3}$ filler particles. Iran. $J$. Mater. Sci. Eng., 8(2), 25.

53. Chow Wen, S. et al. (2008). Flexural properties of hydroxyapatite reinforced poly(methyl methacrylate) composites. J. Reinf. Plast. Compos., 27(9), 945-952, https://doi.org/10.1177/0731684407086506.

54. Tham, W., Chow, W. \& Ishak, Z. (2010). The effect of 3-(trimethoxysilyl) propyl methacrylate on the mechanical, thermal, and morphological properties of poly(methyl methacrylate)/hydroxyapatite composites. J. Appl. Polym. Sci., 118(1), 218-228, https://doi.org/10.1002/app.32111.

55. Oral, O. et al. (2014). Bioactive glass particulate filler composite: Effect of coupling of fillers and filler loading on some physical properties. Dent. Mater., 30(5), 570-577, https://doi.org/10.1016/j.dental.2014.02.017.

56. Canche-Escamilla, G., Duarte-Aranda, S. \& Toledano, M. (2014). Synthesis and characterization of hybrid silica/PMMA nanoparticles and their use as filler in dental composites. Mater. Sci. Eng. C Mater. Biol. Appl., 42, 161167, https://doi.org/10.1016/j.msec.2014.05.016.

57. Upadhyay, Y. (2013). Current state and future perspectives of nanotechnology in dentistry. IOSR J. Pharm., 3(9), 68-71, https://doi.org/10.9790/30130309-68-71. 
58. Xia, Y. et al. (2008). Nanoparticle-reinforced resin-based dental composites. J. Dent., 36(6), 450-455, https://doi.org/10.1016/j.jdent.2008.03.001.

59. Barghamadi, H. et al. (2015). Effects of nanoparticle size and content on mechanical properties of dental nanocomposites: Experimental versus modeling. Iran. Polym. J., 24(10), 837-848, https://doi.org/10.1007/s13726015-0369-5.

60. Safarabadi, M., Khansari, N. \& Rezaei, A. (2014). An experimental investigation of $\mathrm{HA} / \mathrm{AL}_{2} \mathrm{O}_{3}$ nanoparticles on mechanical properties of restoration materials. Eng. Sol. Mech., 2(3), 173-182, https://doi. org/10.5267/j.esm.2014.4.006.

61. Kassaee, M. Z. et al. (2008). Antibacterial effects of a new dental acrylic resin containing silver nanoparticles. J. Appl. Polym. Sci., 110(3), 16991703, https://doi.org/10.1002/app.28762.

62. Sodagar, A. et al. (2012). Effect of silver nano particles on flexural strength of acrylic resins. J. Prosthod. Res, 56(2), 120-124, https://doi.org/10.1016/j. jpor.2011.06.002.

63. Sodagar, A. et al. (2013). The effect of $\mathrm{TiO}_{2}$ and $\mathrm{SiO}_{2}$ nanoparticles on flexural strength of poly (methyl methacrylate) acrylic resins. J. Prosthod. Res., 57(1), 15-19, https://doi.org/10.1016/j.jpor.2012.05.001.

64. Hamouda, I. M. \& Beyari, M. M. (2014). Addition of glass fibers and titanium dioxide nanoparticles to the acrylic resin denture base material: Comparative study with the conventional and high impact types. Oral Health Dent. Manag., 13(1), 107.

65. Shibata, T. et al. (2007). Antifungal effect of acrylic resin containing apatitecoated $\mathrm{TiO}_{2}$ photocatalyst. Dent. Mater. J., 26(3), 437-444, https://doi. org/10.4012/dmj.26.437.

66. Garoushi, S., Lassila, L. V. \& Vallittu, P. K. (2011). Influence of nanometer scale particulate fillers on some properties of microfilled composite resin. J. Mater. Sci. Mater. Med., 22(7), 1645-1651, https://doi.org/10.1007/ s10856-011-4352-1.

67. Afkhami, A., Saber-Tehrani, M. \& Bagheri, H. (2010). Simultaneous removal of heavy-metal ions in wastewater samples using nano-alumina modified with 2,4-dinitrophenylhydrazine. J. Hazard. Mater., 181(1-3), 836-844, https://doi.org/10.1016/j.jhazmat.2010.05.089.

68. Siegel, R. W. et al. (1999). Nanostructure science and technology R\&D status and trends in nanoparticles, nanostructured materials and nanodevices. Boston: Springer.

69. Jo, B.-W. et al. (2007). Characteristics of cement mortar with nano- $\mathrm{SiO}_{2}$ particles. Constr. Build. Mater., 21(6), 1351-1355, https://doi.org/10.1016/j. conbuildmat.2005.12.020. 
70. Li, H. et al. (2000). The crystal structural evolution of nano-Si anode caused by lithium insertion and extraction at room temperature. Solid State Ionics, 135(1-4), 181-191, https://doi.org/10.1016/S0167-2738(00)00362-3.

71. Qing, Y. et al. (2007). Influence of nano- $\mathrm{SiO}_{2}$ addition on properties of hardened cement paste as compared with silica fume. Constr. Build. Mater., 21(3), 539-545, https://doi.org/10.1016/j.conbuildmat.2005.09.001.

72. $\mathrm{Wu}, \mathrm{M}$. et al. (2014). Fabrication and evaluation of light-curing nanocomposite resins filled with surface-modified $\mathrm{TiO}_{2}$ nanoparticles for dental application. Iran. Polym. J., 23(7), 513-524, https://doi.org/10.1007/ s13726-014-0246-7.

73. Drummond, J. L. (2008). Degradation, fatigue, and failure of resin dental composite materials. J. Dent. Res., 87(8), 710-719, https://doi.org/10.1177/ 154405910808700802 .

74. Zhou, M. etal. (2006). Organic overlayer model of a dental composite analyzed by laser desorption postionization mass spectrometry and photoemission. J. Biomed. Mater. Res. A, 77(1), 1-10, https://doi.org/10.1002/jbm.a.30591.

75. Koin, P. et al. (2008). Analysis of the degradation of a model dental composite. J. Dent. Res., 87(7), 661-665, https://doi.org/10.1177/154405 910808700712.

76. Khurshid, Z. et al. (2015). Advances in nanotechnology for restorative dentistry. Mater., 8(2), 717-731, https://doi.org/10.3390/ma8020717.

77. Yang, Q. et al. (2015). Characterization of mesoporous silica nanoparticle composites at low filler content. J. Compos. Mater., 715-722, https://doi. org $/ 10.1177 / 0021998315580830$.

78. Mirjalili, F. (2012). Effect of filler on flexural properties and scanning electron microscopic analysis of fractured surfaces of nanocomposites. Paper presented at the International Conference on Innovations in Chemical Engineering and Medical Sciences (ICICEMS'2012), 26-27 December, Dubai.

79. Mirjalili, F., Chuah, L. \& Salahi, E. (2014). Mechanical and morphological properties of polypropylene/nano $\alpha-\mathrm{Al}_{2} \mathrm{O}_{3}$ composites. Scient. World J., article ID 718765, https://doi.org/10.1155/2014/718765.

80. Mortazavi, V. et al. (2012). The effect of nanoclay filler loading on the flexural strength of fiber reinforced composites. Dent. Res. J., 9(3), 273-280.

81. Chow, W., Tay, H., Azlan, A. \& Ishak, M. (2008). Mechanical and thermal properties of hydroxyapatite filled poly(methyl methacrylate) composites. Paper presented at the The Polymer Processing Society 24th Annual Meeting, Italy. 
82. Hamizah, A. et al. (2012). Mechanical and thermal properties of polymethylmethacrylate bone cement composites incorporated with hydroxyapatite and glass-ceramic fillers. J. Appl. Polym. Sci., 125(S1), https://doi.org/10.1002/app.35295.

83. Roes, A. et al. (2010). Influence of using nanoobjects as filler on functionality-based energy use of nanocomposites. J. Nanopart. Res., 12(6), 2011-2028, https://doi.org/10.1007/s11051-009-9819-3.

84. Akkuş, B. et al. (2015). Effects of $\mathrm{A} 12 \mathrm{O} 3$ and $\mathrm{SiO} 2$ nanoparticles on flexural strength of heat cured acrylic resin. Int. J. Enhan. Res. Sci. Technol. Eng., $4(6), 158-163$.

85. Vojdani, M., Bagheri, R. \& Khaledi, A. A. R. (2012). Effects of aluminum oxide addition on the flexural strength, surface hardness, and roughness of heat-polymerized acrylic resin. J. Dent. Sci., 7(3), 238-244, https://doi. org/10.1016/j.jds.2012.05.008.

86. Shamszadeh, S. et al. (2013). Comparison of flexural strength of several composite resins available in Iran. J. Dent. Sch. Shahid Beheshti Uni. Med. Sci., 31(3), 170.

87. Monteiro, G. Q. d. M. \& Montes, M. A. J. R. (2010). Evaluation of linear polymerization shrinkage, flexural strength and modulus of elasticity of dental composites. Mat. Res., 13(1), 51-55, https://doi.org/10.1590/S151614392010000100012.

88. Culhaoglu, A. K. \& Park, J. (2013). A comparison of the wear resistance and hardness of two different indirect composite resins with a ceramic material, opposed to human enamel. Eur. J. Gen. Dent., 2(3), 274-280, https://doi. org/10.4103/2278-9626.116024.

89. Shokrieh, M. (2014). Residual stresses in composite materials. London: Woodhead Publishing.

90. Miranda, C. B. et al. (2003). A comparison of microhardness of indirect composite restorative materials. J. Appl. Oral Sci., 11(2), 157-161, https:// doi.org/10.1590/S1678-77572003000200013.

91. Mousavinasab, S. M. (2011) Effects of filler content on mechanical and optical properties of dental composite resin. London: InTech.

92. Noort, R. v. (2007). Introduction to dental materials. Edinburgh: Mosby and Elsevier.

93. Singh, G. (2015). Textbook of orthodontics. London: JP Medical.

94. Leitune, V. C. B. et al. (2013). Niobium pentoxide as a novel filler for dental adhesive resin. J. Dent., 41(2), 106-113, https://doi.org/10.1016/j. jdent.2012.04.022.

95. Asopa, V. et al. (2015). A comparative evaluation of properties of zirconia reinforced high impact acrylic resin with that of high impact acrylic resin. Saudi J. Dent. Res., 6(2), 146-151, https://doi.org/10.1016/j. sjdr.2015.02.003. 
96. Monfared, M., Mirdamadi, S. \& Khavandi, A. (2013). Synthesis of new dental nanocomposite with glass nanoparticles. Nanomed. J., 1(2), 107.

97. Hubbezoglu, I. et al. (2007). Microhardness evaluation of resin composites polymerized by three different light sources. Dent. Mater. J., 26(6), 845853, https://doi.org/10.4012/dmj.26.845.

98. Jain, S. et al. (2013). Nanotechnology: An emerging area in the field of dentistry. J. Dent. Sci., 1-9, https://doi.org/10.1016/j.jds.2013.08.004.

99. Junior, R. et al. (2007). Flexural strength and modulus of elasticity of different types of resin-based composites. Braz. Oral Res., 21(1), 16-21, https://doi.org/10.1590/S1806-83242007000100003.

100. Prentice, L. H., Tyas, M. J. \& Burrow, M. F. (2006). The effect of ytterbium fluoride and barium sulphate nanoparticles on the reactivity and strength of a glass-ionomer cement. Dent. Mater., 22(8), 746, https://doi.org/10.1016/j. dental.2005.11.001.

101. Mumcu, E. et al. (2011). Flexural properties of a light-cure and a selfcure denture base materials compared to conventional alternatives. $J$. $A d v$. Prosthodont., 3(3), 136-139, https://doi.org/10.4047/jap.2011.3.3.136.

102. Qasim, S. B., Al Kheraif, A.A. \& Ramakrishaniah, R. (2012). An investigation into the impact and flexural strength of light cure denture resin reinforced with carbon nanotubes. World Appl. Sci. J., 18(6), 808.

103. Balos, S. et al. (2014). Poly(methyl-methacrylate) nanocomposites with low silica addition. J. Prosthet. Dent., 111(4), 327, https://doi.org/10.1016/j. prosdent.2013.06.021.

104. Zhao, J. \& Xie, D. (2009). Effect of nanoparticles on wear resistance and surface hardness of a dental glass-ionomer cement. J. Compos. Mater., 43(23), 2739-2752, https://doi.org/10.1177/0021998309345341.

105. Blackham, J., Vandewalle, K. \& Lien, W. (2009). Properties of hybrid resin composite systems containing prepolymerized filler particles. Oper. Dent., 34(6), 697-702, https://doi.org/10.2341/08-118-L.

106. Faltermeier, A. et al. (2006). Experimental composite brackets: Influence of filler level on the mechanical properties. Am. J. Orthod. Dentofac. Orthop., 130(6), 699.e9-699.e14, https://doi.org/10.1016/j.ajodo.2006.04.023.

107. Lyapina, M. et al. (2016). Application of nanobiomaterials in restorative dentistry. J. IMAB, 22(1), 1050-1055, https://doi.org/10.5272/ jimab.2016221.1050.

108. Pontes, L. F. et al. (2013). Mechanical properties of nanofilled and microhybrid composites cured by different light polymerization modes. Gen. Dent., 61, 30-33.

109. Scougall-Vilchis, R. J. et al. (2009). Examination of composite resins with electron microscopy, microhardness tester and energy dispersive X-ray microanalyzer. Dent. Mater. J., 28(1), 102-112, https://doi.org/10.4012/ dmj.28.102. 
110. Chen, M.-H. et al. (2006). Low shrinkage light curable nanocomposite for dental restorative material. Dent. Mater., 22(2), 138-145, https://doi. org/10.1016/j.dental.2005.02.012.

111. Correr, A. B. et al. (2006). Effect of exposure time vs. irradiance on knoop hardness of dental composites. Mat. Res., 9(3), 275-280, https://doi. org/10.1590/S1516-14392006000300006.

112. Vallittu,P.(2013).Non-metallic biomaterials for toothrepair andreplacement. Cambridge: Woodhead Pub, https://doi.org/10.1533/9780857096432.

113. Kumar, N. et al. (2012). Dental resin-based composites: A transition from macrofilled to nanofilled. J. Pak. Dent. Assoc., 21(1), 39-44.

114. Shah, M. B. et al. (2009). R-curve behavior and micromechanisms of fracture in resin based dental restorative composites. J. Mech. Behav. Biomed. Mater., 2(5), 502-511, https://doi.org/10.1016/j.jmbbm.2008.12.005.

115. Medina, R., Haupert, F. \& Schlarb, A. (2008). Improvement of tensile properties and toughness of an epoxy resin by nanozirconium-dioxide reinforcement. J. Mater. Sci., 43(9), 3245-3252, https://doi.org/10.1007/ s10853-008-2547-8.

116. Xavier, T. A. et al. (2015). Influence of silane content and filler distribution on chemical-mechanical properties of resin composites. Braz. Oral Res., 29, 1-8, https://doi.org/10.1590/1807-3107BOR-2015.vol29.0072.

117. Dittanet, P. (2011). Fracture behavior of silica nanoparticle filled epoxy resin. PhD diss., Lehigh University, Pennsylvania, United States.

118. Wetzel, B. et al. (2006). Epoxy nanocomposites - Fracture and toughening mechanisms. Eng. Fract. Mech., 73(16), 2375-2398, https://doi. org/10.1016/j. engfracmech.2006.05.018.

119. Zhang, H. et al. (2006). Property improvements of in-situ epoxy nanocomposites with reduced interparticle distance at high nanosilica content. Acta Mater., 54(7), 1833-1842, https://doi.org/10.1016/j.actamat. 2005.12.009.

120. Albdiry, M. T., Yousif, B. F. \& Ku, H. (2013). Fracture toughness and toughening mechanisms of unsaturated polyester-based clay nanocomposites. Paper presented at the 13th International Conference on Fracture (ICF 2013), 16-21 June, Beijing.

121. Sun, L. et al. (2009). Energy absorption capability of nanocomposites: A review. Compos. Sci. Technol., 69(14), 2392-2409, https://doi.org/10.1016/j. compscitech.2009.06.020.

122. Nassar, A. \& Nassar, E. (2013). Study on mechanical properties of epoxy polymer reinforced with nanosic particles. Nanosci. Nanoeng., 1(2), 89-93.

123. Sadeghipour, K., Wang, W. \& Baran, G. (2013). Toward improving fracture toughness of particle-reinforced polymer matrix composites. Paper presented at the ASME 2013 International Mechanical Engineering Congress and Exhibition (IMECE2013), 15-21 November, San Diego. 
124. Du, M. \& Zheng, Y. (2007). Modification of silica nanoparticles and their application in UDMA dental polymeric composites. Polym. Compos., 28(2), 198-207, https://doi.org/10.1002/pc.20377.

125. Wang, W., Sadeghipour, K. \& Baran, G. (2008). Finite element analysis of the effect of an interphase on toughening of a particle-reinforced polymer composite. Compos. A, 39(6), 956-964, https://doi.org/10.1016/j. compositesa.2008.03.016.

126. Kruzic, J. J. et al. (2003). Crack blunting, crack bridging and resistancecurve fracture mechanics in dentin: Effect of hydration. Biomater., 24(28), 5209-5221, https://doi.org/10.1016/S0142-9612(03)00458-7. 